\title{
ENFOQUES TEÓRICOS EN ARQUEOLOGÍA ${ }^{1}$
}

\author{
THEORETICAL APPROACHES IN ARCHAEOLOGY
}

por

ALMUDENA HERNANDO GONZALO

RESUMEN Se pretende presentar un esquema claro y exhaustivo de las opciones "teóricas" que se están utilizando en el estudio del pasado, a fin de clarificar un panorama algo confuso. Se ha optado por una exposición "histórica" del desarrollo de la disciplina, de forma que el pasado permita entender la oferta teórica del presente, y ésta, a su vez, las tendencias a las que parece encaminarse la materia. Se perfilan distintos enfoques inspirados en fuentes aparentemente lejanas de la Prehistoria, para profundizar en el entendimiento de nuestra disciplina como resultado de todo el contexto económico-social en el que se desarrolla.

ABSTRACT This paper intends to outline comprehensively the range of theoretical approaches currently used in the study of the past on the assumption that some confusionism has appeared recently in the debate. Particular emphasis is made on the influence that modern socio-economic contexts have on archaeological views of the past.

\section{INTRODUCCION}

La situación de marginalidad que ha vivido la tradición académica española con respecto a los movimientos epistemológicos de otras áreas, sigue haciendose sentir en la formación de la nuevas generaciones de arqueólogos. El sistema tiende a reproducirse a sí mismo, por lo que sólo la presencia de profesores particularmente interesados en la reflexión teórica permite el desarrollo de una actitud "reflexiva" y crítica del alumno hacia su pasado.

Ello conduce a un evidente y lógico desajuste entre una sociedad con un ritmo de avance y transformación vertiginoso y un inmovilista sistema académico que no puede ofrecer al alumno lo que

1. Este artículo constituye un resumen parcial de un curso sobre "Enfoques teóricos en Arqueología" celebrado durante el mes de enero de 1991 en Madrid, como parte de un amplio programa de especialización para licenciados, organizado por la Fundación Ortega y Gasset y el Ayuntamiento de dicha ciudad. 
éste necesita y demanda: una base teórica seria para iniciar y sobre la que asentar su reflexión sobre el pasado, unos conocimientos sólidos sobre Arqueología Científica o Arqueometría y una formación relacionada con la Arqueología contractual o “de gestión" (v. Ruiz Zapatero, 1991), la oferta de trabajo más generalizada. El resultado es que nuestras universidades no están preparadas, por el propio diseño de sus planes de estudio -y lo que es peor, por el que se prevee para la mayoría de ellas en el futuro-, para formar adecuadamente a las nuevas generaciones de arqueólogos que, de ese modo, pasan a convertirse, en la mayoría de los casos, y tras largos años de deficientes estudios, en frustrados autodidactas.

A mi juicio, el problema reviste enorme trascendencia, pues la falta de formación nos dificulta enormemente decidir con claridad cuál es o va a ser nuestra posición frente al estudio del pasado. Incluso nuestra decisión sobre la propia posibilidad de "estudiar el pasado", o incluso nuestra actitud ante la planificación de la arqueología de gestión. Ahí está el debate, o quizás sea mejor decir la falsa oposición -a muchos niveles (v.infra)- arqueología de investigación/arqueología de gestión (Ruiz, 1.989, Martínez Navarrete, 1990) ${ }^{2}$ y el concepto tan limitado que los licenciados suelen tener de la segunda. De ésta proceden las máximas ofertas de empleo, lo que hace prever un futuro poco favorable para el desarrollo de la reflexión teórica en nuestro país. Por otra parte, en este último campo se advierte una avalancha de bibliografía, posiciones y teorías que, llegadas a nuestro país desde fuera, provoca una ligera sensación de pérdida y desconcierto, conducentes, en general, a la huida, en quienes no han tenido la fortuna de contar con algún "guía espiritual" a lo largo de su iniciación en la profesión.

Al publicar este artículo, pretendo clarificar un poco el panorama de la "oferta" teórica de la Arqueología actual ${ }^{3}$. Y con ello, ya estoy indicando que una de las más importantes cuestiones que podría plantearse en esta última queda fuera del alcance de este trabajo. Sólo pretendo esquematizar, lo más claramente posible, las distintas posiciones o "teorías" que ahora se están utilizando para abordar el estudio del pasado prehistórico, enmarcándolas en sus respectivos contextos de desarrollo histórico ${ }^{4}$, por si de algo pudiera servir a quienes estuvieran pensando en la huida. Es decir, se va a tratar aquí de "teorías en Arqueología", pero no de Teorías de la Arqueología, o lo que es lo mismo, de la Filosofía de la Arqueología. Quiero decir que, en este texto, el concepto de teoría se va a identificar, como usualmente, aunque no correctamente sucede, con el de modelo o método, sin abordar, por ello, la principal cuestión de la Arqueología teórica: la relación entre conocimiento e interés, la posibilidad de independencia "científica" de la Arqueología, la vinculación, en fin, entre Arqueología y Sistema, todo lo cual es lo mismo que decir la reflexión auto-crítica. Porque la principal cuestión que puede llegar a plantearse en Arqueología es si su mera existencia no es en realidad un desarrollo del sistema, si existe la posibilidad de independencia del arqueólogo a ese respecto (v. Vicent, 1.991, Criado, Nocete y Vicent, 1.991).

Así pues, no voy a moverme en un nivel teórico-crítico, sino en uno metodológico-descriptivo que, aunque de menor alcance, también considero importante para generalizar la reflexión sobre nuestro objeto de estudio.

Comenzaré por resumir la historia de la disciplina, sin cuyo conocimiento resulta difícil llegar a comprender la situación actual. Pero antes, y como introducción imprescindible al texto que sigue, creo

\footnotetext{
2. Agradezco a M.I. Martínez Navarrete la consulta de este texto, inédito.

3. Entiéndase "Arqueología" en el sentido amplio de la tradición americana (TRIGGER, 1978: 3).

4. De hecho, he seguido en buena medida, sobre todo en la elaboración de la Historiografía, el clarificador trabajo de Trigger (1989)
} 
necesario insistir una vez más en que no existe la observación objetiva (Wartofsky, 1.978). Nuestra percepción de la realidad está determinada culturalmente, socialmente, individualmente, pues para construirla es necesario seleccionar entre los infinitos estímulos que nos llegan del exterior; y ¿cómo puede pretenderse objetividad en una selección?

Si esto es así en la vida diaria, qué decir de la elaboración de nuestros juicios sobre el pasado, de nuestra actividad profesional. El arqueólogo dedica sus esfuerzos a intentar salir con éxito del quíntuple salto mortal -sin red- que supone, intelectualmente, su labor: la arqueología es la única ciencia social que carece de información directa sobre el comportamiento humano, su objeto de estudio. Esta es su principal peculiaridad y ésta es, también, su mayor dificultad. El arqueólogo intenta conocer aspectos de la cultura del pasado a través de los restos materiales que de ella se conservan, lo que supone un triple grado de reducción: del comportamiento humano en el pasado a su manifestación material, de ésta a su conservación a través del tiempo, y de ésta, a lo que el arqueólogo recupera. Ya Clarke en 1.973, señaló que la arqueología pasaría a convertirse en una "forma irresponsable de arte" si no desarrollaba una teoría que relacionara los restos materiales con el comportamiento humano, si no se reconocía que el arqueólogo posee sólo una muestra reducida de lo que se propone estudiar (Trigger, 1.989:358). Así pues, en el presente juzgamos lo que en el presente se conserva, tras sus transformaciones desde su formación en el pasado. Tan amplio grado de dificultad sólo puede salvarse a través de la inferencia.

Ahora bien, por "teoría" pueden entenderse diversos niveles de inferencia. Desde ciertas posiciones, se ha diferenciado la "teoría de la reconstrucción", la "teoría metodológica" y la "teoría social" (Schiffer, 1.988), la última de las cuales acogería las leyes globalizadoras referentes a las posiciones adoptadas para explicar la variabilidad del comportamiento humano y el cambio (Ibidem, 464). Tales posiciones derivan de las asunciones básicas que utilizamos para juzgar el propio presente y la naturaleza general de la Historia. No es casualidad que los paradigmas dominantes se hayan ido transformando al compás de la situación económico-político-social del mundo occidental, del que es también "producto" el arqueólogo. Como señala F. Criado (1.988b: 52-53) la Nueva Arqueología, conjugada con la Teoría de Sistemas apareció en los años 60, cuando el capitalismo experimentaba su mayor crecimiento y el optimismo economicista inundaba la sociedad; la Ecología Cultural se desarrolló definitivamente en los 70 , correspondiéndose con la crisis del petróleo, energética y económica en general, y el post-estructuralismo impacta en Europa en los años 80, afinándose progresivamente el énfasis semiótico en los 90 , en la convicción de que todo discurso y todo pensamiento son directamente un acto, lo que pone el peso en el presente y olvida el futuro, tan pesimistamente negado por la postmodernidad.

¿Cómo rechazar la evidencia de que nuestros pensamientos están determinados por las preocupaciones y los intereses de nuestra clase social, de las instituciones donde trabajamos, de nuestro tiempo en general? Así pues, un análisis de los presupuestos con que trabajamos parece condición sine qua non para reducir los sesgos que imprimimos a nuestra visión del pasado y para posibilitar la crítica constructiva que contribuya a perfeccionarla. Al menos quedarán especificadas las condiciones de actuación, aunque resulte imposible conseguir la asepsia y falaz pretenderlo.

\section{EL PASADO}

Pero no sólo los cambios del presente han transformado la visión del pasado. Renfrew (1.982) divide la historiografía sobre la "explicación" en Arqueología en tres grandes fases: "el primer fermento" del tercer cuarto del s. XIX, el "largo sueño" y el "gran despertar" que, a su juicio, habría supuesto la aparición de la Nueva Arqueología en los años 60. 
Por su parte, Willey y Sabloff (1.974) diferenciaron cuatro períodos sucesivos: Especulativo, Clasificatorio-Descriptivo, Clasificatorio-Histórico y Explicativo, el último de los cuales habría comenzado en los años 60 , de forma que a lo largo de la mayor parte de su desarrollo, habrían prevalecido los objetivos descriptivos y clasificatorios (Trigger, 1.989:4).

El desarrollo de nuestra disciplina, siguiendo a Trigger (Ibidem: 5-7), es visto por algunos (Clarke, 1.968 , por ej.) como un conjunto de datos ajustados a inadecuadas subteorías no estructuradas en un sistema global hasta los años 60 , lo que les lleva a calificar su estado de pre-paradigmático previo a esa fecha. Como es bien sabido, Kuhn (1.970) definió el paradigma como un canon aceptado de práctica científica, sustentado por una comunidad y propagado a través de revistas y manuales controlados por esa comunidad. Sin embargo, un análisis detenido de la Historia de nuestra disciplina demuestra, como tendremos oportunidad de ver, la profunda coherencia de las posturas defendidas desde su inicio.

Otros arqueólogos (Sterud, 1.973) contemplan, en efecto, la evolución de la Arqueología como una sucesión de paradigmas en constante superación a través de las revoluciones científicas que hombres como Thomsem, Montelius, Gordon Childe o Binford protagonizaron. Otros (Willey y Sabloff, 1.974, Meltzer, 1.979) niegan la existencia de revoluciones en la ciencia en general y en la Arqueología en particular, definiendo su desarrollo como un cambio gradual que responde a la constante expansión de la base empírica y a la progresiva elaboración y refinamiento de un corpus, ya existente, de teoría. El proceso es lineal, acumulativo e inevitable, exactamente al contrario de la definición que de él da un cuarto grupo (Piggot, 1.950, Hunter, 1.975), para el que la teoría arqueológica no avanza para acoger de manera cada vez más ajustada la creciente base empírica, sino que sufre transformaciones nolineales, y a veces imprevisibles, que dependen en general de factores externos a su desarrollo. Por fin, un último grupo (Orme, 1.973) duda de que realmente se produzcan transformaciones, innovaciones, en el desarrollo de la Arqueología, en la idea de que su historia es únicamente la expresión recurrente de problemas cíclica y alternativamente olvidados, lo cual significa negar el valor al marco teórico en el que se desarrollan que es lo realmente significativo.

De cualquier modo, y al margen de cómo concibamos la evolución de su historiografía, lo cierto es que ésa ha oscilado entre dos posiciones esenciales, divergentes entre sí por el distinto concepto de cultura que cada una implicaba (Vicent, 1.985): una considera que la cultura es un fenómeno externo a la realidad del individuo, y que por tanto éste, que lo sostiene y lo expresa participando de él, no puede determinar (piénsese por ejemplo en nuestra concepción del lenguaje - ¿podemos determinar su transformación o simplemente nos limitamos a expresarnos a través de un fenómeno que tiene sus propias leyes de evolución, sus propios procesos de cambio?-). La otra la considera un producto de la mente del individuo, sin que por tanto, existan leyes generales de explicación. Todas las perspectivas evolucionistas, materialistas, pertenecen a la primera opción, mientras que todos los idealismos y concepciones historicistas de la Historia se adscriben a la segunda (Hernando, 1.988b).

Pues bien, el primer gran bloque interpretativo en Prehistoria fue protagonizado por el "evolucionismo clásico" o "unilineal", cuyos representantes abarcaban toda la gama de disciplinas entonces practicadas: Darwin, Spencer, Marx, Morgan, Freud...

Como ya he señalado en otro lugar (Hernando, e.p.) el "evolucionismo clásico", llamado también "darwinismo social", intentaba demostrar que la herencia jugaba un papel causal en la conducta humana, que los factores genéticos podían provocar cambios culturales, lo que, evidentemente, tiñó de reduccionismo biológico y de racismo los estudios de la época, en los que se alcanzaron cotas tan excesivas que abocaron en el abandono del modelo. No cabe duda de que el espíritu colonial del momento jugaba un papel determinante en la aceptación de tal perspectiva, cuyo fin último era demostrar la unidad psíquica de todos los grupos humanos, quienes, por consiguiente, habrían de pasar por 
los mismos estadios de evolución. El hecho de que sólo algunos pueblos hubieran sufrido el máximo de transformaciones culturales demostraba su superioridad genética y evolutiva, lo que justificaba el ejercicio de su poder sobre los demás.

Coincidiendo con la generalización de este modelo, Thomsem desarrolla en Arqueología el famoso sistema de las Tres Edades, cuya perfecta adecuación al espíritu de la época llevó a su adopción como base de la clasificación de los períodos prehistóricos, ampliándose de esta forma sus implicaciones iniciales que, como se sabe, sólo afectaban a la ordenación de los restos arqueológicos acumulados en los fondos del Museo de Copenhague.

Posteriormente, en la segunda mitad del s. XIX, el esquema se transformaría en un sistema cuatripartito, con el que se daría origen al concepto de "edad": Mortillet sugiere la división de la Prehistoria en Edad de la Piedra Tallada, Pulimentada, del Bronce y del Hierro, mientras que Lubbock propone los términos de Paleolítico, Neolítico, Bronce y Hierro.

Así pues, la Prehistoria nace en el s. XIX dentro de un ambiente ideológico gobernado por el reduccionismo biológico y el Evolucionismo Unilineal, a partir de dos raíces distintas y convergentes: por un lado, el interés generado en Dinamarca por explicar las características del Neolítico, la Edad del Bronce y la Edad del Hierro, y el paso de unos a otros. Por otro los estudios del Paleolítico, desarrollados en Francia e Inglaterra cincuenta años después, relacionados con la investigación del origen del hombre y modelados dentro del marco de las ciencias naturales. Ambas tendencias confluirían para ofrecer una visión del pasado basada en identificación entre evolución tecnológica y desarrollo moral, profundamente gratificante para la clase media y alta de la época -que pagaba la investigación, investigaba y constituía el público receptor (Trigger, 1.989: 108-109)-. De este modo, estos grupos podían autocontemplarse /complacerse como resultado del "progreso que era inherente a la naturaleza humana y quizás, incluso, a la propia constitución del Universo", justificando así sus abusos sobre los pueblos indígenas, limitados en sus capacidades para participar de dicho progreso (Ibidem).

Sin embargo, a fines del s. XIX van a confluir varios factores que obligarán a un cambio en la perspectiva de estudio: por un lado, los resultados de la revolución industrial desilusionan a los que habían cifrado en ella sus esperanzas, decayendo la fe en el "progreso" de la Humanidad. Por otro, la progresiva industrialización de Europa conducía al aumento de la competitividad entre las naciones por adueñarse del mercado y, por fin, los excesos del evolucionismo unilineal, clásico hacían fijar la atención sobre el aspecto contrario: las divergencias culturales, las peculiaridades grupales, la etnici$d a d$. Todo ello lleva a un aumento del nacionalismo en toda Europa, que busca cualquier instrumento para justificarse. Como no podía ser menos, la Arqueología jugará un papel clave en el proceso, pues el Pasado de cada pueblo tenía que ser interpretado de un modo ajustado a las necesidades del Presente, probándose esa realidad ante las demás naciones. Los restos materiales se van a convertir, así, en objetivo prioritario de los arqueólogos, que se ven plenamente apoyados por las instituciones en la persecución de su fin último: delimitar las áreas culturales que desde el principio de los tiempos han abarcado sus respectivos pueblos. A ello contribuye, como otro de los factores a los que antes aludía, la recuperación de crecientes cantidades de material arqueológico debido a la industrialización de Europa -y consiguiente construcción de carreteras, fábricas, etc.- el desarrollo de los museos y centros de investigación dentro del espíritu ilustrado de la época y el apoyo institucional concretado en la dotación de puestos docentes en las Universidades, hasta entonces inexistentes (IBIDEM: 148-9).

De este modo, dado el rechazo al evolucionismo por sus propios excesos, el pesimismo que de ello se derivó (no hay leyes que expliquen al hombre) y las necesidades socio-políticas del momento, el esquema evolucionista de "estadios" como sistematización del desarrollo cultural, es sustituido por el de "áreas" o "circulos culturales", triunfando así la concepción idealista de la escuela Histórico- 
Cultural alemana, heredera de las ideas de Ratzel, Graebner, Schimidt, Boas y Elliot Smith 5 (v. Harris, 1.979).

Para esta escuela (v. Hernando, e. p.) la secuencia básica de desarrollo cultural sólo se había producido una vez, transmitiéndose a los demás territorios por difusión, lo que permitía ordenar todas las culturas y seguir en un mapa la dispersión hasta encontrar el área original. Ningún mecanismo explicativo podía convenir más a los gobiernos nacionalistas europeos, que, por supuesto, intentaban identificar, a través de los estudios arqueológicos, el área o Kreis original con su propio territorio, lo que demostraría su superioridad étnica sobre los demás pueblos. Especialmente peligroso resultó el caso alemán, a cuyas pretensiones nazis contribuyó la interpretación "étnica" del arqueólogo Kossina (1.858-1.932) y su puesta en práctica por gestores como H. Reinerth o el austriaco O. Menghin. Estos últimos contribuyeron a legitimar el III Reich distorsionando, de forma consciente, los datos arqueológicos (Arnold, 1.990: 471). Las consecuencias para nuestra disciplina son claras: la atención queda centrada en el análisis de los materiales, sus lugares de origen, sus rutas de difusión, ... Tipología y cronología como objetivos únicos de estudio, porque son ellos los que "explican" la historia.

En España, Bosch Gimpera fue el mejor representante de esta tendencia, generalizada en todo el mundo occidental, aunque a veces haya sido considerado "evolucionista" por oponerse a los defensores de la Teoría Colonial (Hernando, 1.988: 78-135; e.p.).

Derivado de esta escuela, el difusionismo, como explicación de los cambios culturales, queda presente en la tradición disciplinar con sus implicaciones "normativistas" (Idem, 1.987: 172-3). Aunque de una manera menos rígida se seguirá buscando explicar el acontecimiento individual (único que se contempla al no existir leyes generales que expliquen la Historia) por el análisis de su particularidad y su semejanza o diferencia con lo que le antecede o rodea.

Rathje y Schiffer (1.982: 302) han sugerido que la Teoría difusionista se hizo popular en arqueología en una época en la que por todas partes podía verse la eficacia de sus mecanismos: la constante aparición de nuevos productos en la industria occidental y su expansión -como poderes coloniales-por todo el Tercer Mundo, así como la aplastante evidencia de la migración como mecanismo transmisor de cultura a través de las puertas abiertas de la Isla de Ellis (Schiffer, 1.988: 467). En el mismo sentido, C. Alonso del Real (1.987) interpreta del modo siguiente la realidad: "difusionismo colonialista nació dónde y cuándo nació (en la Inglaterra tardovictoriana); y la idea de la difusión de productos cuando la gran industria occidental exportaba cosas (autos, medicamentos). La generalización de la venta de patentes, nos ha hecho pensar más bien en la difusión de estímulos". En efecto, el floreciente pasado colonial español puede ser el factor clave para explicar el éxito y mantenimiento de la Teoría Difusionista en nuestro país; resultaba convincente porque era coherente (Hernando, e.p.).

Mientras tanto, y al igual que la Escuela Histórico Cultural alemana en Europa, la Escuela Boasiana (por su inspirador F. Boas) representaba en los EE. UU. el intento mas serio de oposición al Evolucionismo clásico. Sin embargo, al igual que él, su desarrollo acabó convirtiéndose en una serie de excesos, en este caso idealistas, que provocaron los primeros ataques de W. Taylor (1.948) en su "A Study of Archaeology". De este modo, se abre la puerta a la orientación funcionalista, continuada como luego veremos, por J.H. Steward y cuyo producto final será la tan discutida Nueva Arqueología.

Con ello entramos en una nueva oscilación del péndulo, al encontrarnos así con las bases del "evolucionismo multilineal" que, al contrario del idealismo precedente, intentará a su vez, superar las deficiencias del Evolucionismo Clásico. Sin embargo, habrá que esperar hasta la llegada de V. Gordon

5. Elliot Smith (1871-1937 formó un grupo en la Escuela de Manchester que se constituyó en el máximo representante del difusionismo europeo. El único origen de la civilización se localizaba, a su juicio, en Egipto, desde donde se habría difundido al resto del mundo. 
Childe (1.893-1.957) para que este nuevo modelo sea incorporado al estudio de la Prehistoria. Este australiano, intensamente comprometido en actividades políticas de izquierda durante gran parte de su vida, comenzó su actividad profesional interesándose, al modo tradicional, por el origen de los indoeuropeos, al modo tradicional, lo que entonces significaba, particularista-histórico. Sin embargo, aún dentro de esta posición, contribuyó de manera decisiva al avance de la arqueología al utilizar de forma sistemática, por primera vez, en 1.925, el concepto de cultura arqueológica, tomado de Kossina, pero liberado de sus connotaciones racistas. Childe subrayó, como nadie antes lo había hecho, la necesidad de definir empíricamente cada cultura en términos de elementos materiales recurrentemente asociados, delimitando su estratigrafía y sincronismos. De esta manera, interpretó la prehistoria europea como un complejo mosaico de culturas interrelacionadas (Trigger, 1.989: 170) desarrollando un esquema que ya no sería abandonado.

A partir de 1.936 Childe adopta una nueva perspectiva teórica, el evolucionismo multilineal, debido al menos a una doble influencia: las lecturas de los evolucionistas clásicos Marx, Engels y Morgan, y la llegada de B. Malinowski, con su firme oposición funcionalista al enfoque historicista tradicional (Alcina, 1.989:40) a la cátedra de Antropología Social de la Universidad de Londres. Desde esta nueva posición, son, de nuevo, diversas y de enorme trascendencia las aportaciones que hace al campo de la Arqueología: el concepto evolucionista de "etapa", frente al clásico de "edad" (lo que evitará muchas de las problemáticas connotaciones de este último); un concepto funcionalista de cultura -ésta va a ser contemplada desde ahora como un todo orgánico, y no como un conjunto mecánico y desordenado de rasgos-; una mayor importancia al medio y a la ecología, etc. etc..

Sin embargo, será Leslie A. White quien, en los años 40, consiguió definitivamente el triunfo del neo-evolucionismo en el campo general de la Antropología. El fue quien definió la cultura como un sistema integrado por subsistemas, en el cual todos los rasgos están interrelacionados; el autor de la famosa definición de cultura como un "medio extrasomático de adaptación", y el profesor de un joven alumno de nombre L.R. Binford. Sus trabajos son recogidos y continuados por J. H. Steward, quien, entre 1.945 y 1.955 , confirma la hegemonía de este modelo en la Antropología americana. En 1.959, J. Caldwell publicó un artículo en la revista Science titulado "La nueva arqueología americana", donde sintetizaba, por primera vez, las nuevas tendencias que comenzaban a definir esta disciplina, enormemente dependiente de la Antropología en los EE.UU.. Entre ellas citaba (Trigger, 1.989: 294-6): a) un creciente interés por la ecología y los patrones de asentamiento (acogiendo los desarrollos del "ambientalismo" inglés y de la "arqueología del asentamiento" americana (Alcina, 1.989: 58)); b) las culturas arqueológicas no podían ser consideradas, por más tiempo, una suma desordenada de artefactos, cada uno de los cuales era igualmente representativo de la cultura, sino que tenían que ser tratados como sistemas orgánicos, funcionalmente integrados; c) hay leyes que explican la historia. A pesar de existir infinidad de hechos particulares, sólo hay unos cuantos procesos históricos generales; d) el principal objetivo del arqueólogo debe ser explicar el cambio cultural, basándose en el análisis de los procesos generales.

Así pues, el concepto de cambio procesual fue tomando fuerza progresiva hasta imponerse definitivamente a lo largo de la década comprendida entre aquel trabajo de V. Taylor (1.948) y éste de Caldwell. A principios de los 60 , el nuevo modelo neo-evolucionista se había convertido, sin ninguna duda, en el nuevo paradigma de la investigación antropológica americana, divulgado y apoyado por los jóvenes investigadores que en él se habían formado, Uno de ellos, como antes decía, era L.R. Binford, quien terminó de perfilar el enfoque que, a partir de entonces habría de popularizarse como "Nueva Arqueología" (NA), y que constituyó un verdadero revulsivo -el "gran despertar" de Renfrew, gracias al cual se aceleró enormemente el desarrollo de la disciplina. 
Binford esquematizó el programa de la N.A. en dos artículos titulados "Archaeology as Anthropology" (1.962) y "Archaeological systematics and the study of culture process" (1.965), considerados desde entonces casi como los "idearios" de la escuela. Por su parte, Carke (1.968) desarrolla la idea de cultura de L.A. White, introduciendo los principios de la Teoría General de Sistemas en el estudio de la cultura. A su juicio, dos grandes sistemas -el sociocultural y el ambiental- interactúan de forma dinámica y continua sobre una base de probabilidades. Cada uno de ellos se halla constituído a su vez por distintos subsistemas -social, religioso, económico, de cultura material, etc. en el primer caso y de fauna, flora, clima, geológico, etc., en el segundo. Cualquier cambio en los atributos de uno de ellos provoca cambios en el conjunto del sistema, dada la interrelación e interconexión existente entre ellos, lo que le lleva, por otra parte, a una capacidad de autorregulación y autocontrol entendida, en ocasiones, como adaptación. Esta orientación tendrá un peso decisivo en la formación de las posiciones "procesuales" que, como veremos, se constituirán como herencia natural de la Nueva Arqueología.

V. Fernández (1.989: 32) resumía con mucha claridad los principales rasgos de esta tendencia: consideración de la cultura como un sistema adaptativo al medio. Ello significa que la cultura no se transforma por contacto con otras culturas, como pretendían los difusionistas, sino por influencia ambiental, lo que les lleva a defender la existencia de procesos generales de cambio, leyes que permiten entender el comportamiento humano y su relación con el exterior. Consideran que estas leyes son las mismas que gobiernan los procesos de transformación de las Ciencias Naturales (positivismo), por lo que eligen el método de razonamiento hipotético-deductivo. Por último, creen firmemente en la posibilidad de poder reconstruir todo el sistema cultural a partir de los restos materiales que de él han quedado, lo que les lleva a desarrollar como nunca hasta entonces se había hecho, sistemas cuantitativos de análisis, que permiten integrar y relacionar la mayor cantidad posible de información. Así pues, dados estos presupuestos de partida, las publicaciones de la N.A. coincidirán en su esfuerzo por a) investigar la estructura teórica de la arqueología, b) establecer pautas rigurosas de interpretación de los datos arqueológicos y c) probar nuevos métodos de análisis (Trigger, 1.978: 19). Ello conduce a una renovación a todos los niveles, de nuestra disciplina, si bien no debe ignorarse que dentro de unas estrictas pautas de racionalidad que, en realidad, impedían la verdadera discusión teórica (v. infra). De hecho, en su esfuerzo por hacer de la Arqueología una disciplina científica, dotándola de una coherencia teórica y metodológica de la que, hasta entonces, había carecido, algunos nuevos arqueólogos cometieron excesos que muy pronto habrían de pagar. Fritz y Plog (1.970) y Watson, LeBlanc y Redman (1.974), entre otros, constituyeron una rama especial de la N.A. denominada por Flannery (1.973) de "la ley y el orden", debido a sus estrictos e inflexibles planteamientos. Estos consistían, fundamentalmente, en la utilización del método de razonamiento hipotético-deductivo de Hempel, que pocas veces podía aplicarse adecuadamente, dada la naturaleza de la investigación, y que en la mayor parte de los casos, sólo daba lugar a la formulación de leyes triviales (denominadas por Flannery y sus críticos "de Micky Mouse") o tautológicas.

Así pues, mientras que 1.965 o 1.968 , fechas en que Binford y Clarke publican dos de sus obras más destacadas, podría considerarse como la del nacimiento oficial de la N.A., 1.973 puede considerarse la de su defunción, provocada por el ataque feroz de dos artículos aparecidos en este año, firmados por Flannery (v. supra) y Morgan, y tras los que la N.A., como grupo homogéneo, tendencia unitaria, desaparece. De ella quedarán los restos, más matizados y con muchas más variantes, que se incluyen bajo el epígrafe general de "arqueología procesual", y que luego veremos.

La reacción contra la N.A. en los años 70 seguirá un doble sentido: "uno hacia lo general y, por tanto, hacia lo comparativo; el otro hacia el análisis específico del contexto y, por tanto, en último término, hacia lo único" (RENFREW 1.982: 21). En realidad, la disyuntiva estriba en la posición del 
arqueólogo frente a la conceptualización de la cultura que señalaba al principio, y por tanto, en su aceptación o rechazo de la existencia de leyes que expliquen la Historia (Martínez Navarrete, 1.989: 7). Por un lado aparecerán sus defensores, dedicados a estudiar los procesos internos de cambio, la dinámica de los procesos, desligándolos en general del determinismo medioambiental que caracterizaba a la N.A. (Arqueología procesual y materialismos) y, por otro, sus detractores, surgidos en la década de los 80 bajo la influencia del estructuralismo francés, quienes reclaman la subjetividad y el relativismo de la interpretación arqueológica.

\section{EL PRESENTE}

Por consiguiente, un esquema-resumen de la diversificación teórica que actualmente existe en Arqueología, podía ser el siguiente:

1. Aproximación historiográfica tradicional (arqueología tradicional o positivista).

2. Arqueología procesual (N.A., neo-positivismo, arqueología funcionalista, Teoría de Sistemas).

3. Aproximaciones materialistas.

4. Arqueología radical.

\section{Aproximación historiográfica tradicional}

Corresponde a la perspectiva historicista, dominante antes de la aparición de la N.A. en los EE.UU.. En Europa, sin embargo, el difusionismo siguió constituyendo el principal mecanismo de explicación del cambio cultural hasta mucho después. Al margen de España, que por su aislamiento epistemológico lo ha mantenido hasta nuestros días como paradigma casi exclusivo y que, por tanto, ofrece infinitos ejemplos de esta tendencia, hay dos escuelas europeas destacadas: la alemana y la francesa, muy influenciadas ambas por sus respectivas tradiciones de estudio y por el peso del nacionalismo en ambas.

Mientras que en Europa se trata de una perduración monótona y cómoda de presupuestos sobre los que, en la mayor parte de los casos, no se reflexiona, en EE. UU. la tendencia va a intentar recuperarse como reacción -entre las demás, pero casi sin fuerza- a la N.A.. J. Hawkes (1.968) se convierte en su principal representante con su emblemático "The proper study of mankind", publicado por Antiquity en aquel año de gracia de la N.A.. En él, la autora critica el cientifismo de esa tendencia, reivindicando el humanismo como soporte ideológico y teórico de la Arqueología.

Su inmovilismo y declarada falta de interés por la teoría ha tenido, a mi juicio, muy negativas consecuencias en la formación de las generaciones recientes de arqueólogos en nuestro país, que, de este modo, eran mantenidas al margen de los activos movimientos que estaban teniendo lugar en otros países, en especial, el mundo anglosajón. Ahora bien, hay que reconocer con V. Fernández (1.989: 228) que fue precisamente su exclusivo interés en el dato el que provocó el desarrollo de muchos de los sistemas de cuantificación y Arqueología analítica que ahora se utilizan, atribuyéndolos, erróneamente en ocasiones, a la N.A..

\section{Arqueología procesual}

Bajo esta denominación se incluyen enfoques diversos que coinciden en una preocupación dominante por el estudio de los procesos de cambio en una cultura dada, sus bases generalizadoras y su 
despreocupación por la conducta individual. Se trata del desarrollo de la N.A. que, como vimos, comienza a desaparecer como tendencia unitaria a partir de 1.973. Sus representantes adoptan posiciones diversas, caracterizadas en general por una postura más ecléctica y menos agresiva, que incluye el rechazo del método nomológico-deductivo de Hempel, sustituyéndolo por la explicación sistémica y las leyes probabilísticas. No obstante, la tendencia se mantiene bajo la denominación de Nueva Arqueología en el contexto extra-europeo, fundamentalmente americano, tanto al norte como al centro y sur del continente.

La mayor parte de los investigadores "procesuales" utilizan la Teoría General de Sistemas (TGS), si no ya como cuerpo de la teoría general, así al menos, como base conceptual de muchas de sus explicaciones, como revela la contaminación de su vocabulario. Términos como "sistema", "parámetros del sistema", "trayectoria", "retroalimentación positiva o negativa", "flujo de energía, de información", "entropía", "homeóstasis", "morfogénesis", etc., constituyen buena parte del léxico de sus publicaciones, mientras que la unidad política o la región y su población son vistos como sistemas donde el cambio se produce como una respuesta homeostática al cambio exógeno por unos, y como esencialmente endógeno, por otros (Renfrew, 1.982: 11).

Según la TGS, la cultura es un sistema integrado por una serie de subsistemas relacionados, recogiendo así las ideas ya planteadas por Lelie A. White. La desarrollaron Binford en 1.965 y Clarke en 1.968. El último de los cuales estableció un listado de propiedades de los sistemas aplicables a las culturas arqueológicas. En general, no se utiliza en forma estricta el paradigma cibernético, sino que suelen propugnar exclusivamente la supuesta propensión o tendencia del sistema o subsistemas a comportarse, bajo ciertas circunstancias, de una forma concreta, sin constituir, muchas veces, afirmaciones precisas (Ibidem). La obra más típica de la utilización de la TGS es la Tesis Doctoral de Renfrew "La emergencia de la civilización en el Egeo", de 1.972.

En su mayoría, los arqueólogos procesuales son decididos defensores de la conceptualización del cambio cultural como esencialmente endógeno, considerando que sólo se producirá si resulta adaptativo y beneficioso para el sistema, y si cumple una función positiva que contribuya a aumentar su coherencia y estabilidad. Por ello, se les denomina también "funcionalistas", contándose entre ellos Chapman o Mathers -quienes han prestado atención a la Península Ibérica- o, por supuesto, Renfrew.

Fiel a esta tendencia, Renfrew ha ido, sin embargo, modificando y modernizando progresivamente su posición. Así por ejemplo, declara (Renfrew, 1.989:34) que la arqueología procesual está pasando de una fase procesual-funcional a una procesual-cognitiva, cuyo desarrollo prevee para el futuro. Desde esta nueva "versión", sigue defendiendo (Ibidem: 39-40) la necesidad de un método científico para conocer el pasado, la búsqueda de generalizaciones que permitan explicaciones (método hipotéticodeductivo), la existencia de una realidad objetiva de ese pasado, el rechazo de la utilización de las convicciones políticas actuales del investigador como criterio de validez de sus juicios sobre el pasado, el interés prioritario del estudio de los procesos y no de los acontecimientos únicos, etc.. Pero a su vez, acepta propuestas introducidas en el análisis por investigadores post-procesuales que, en general (v.infra) se refieren a un rechazo a un positivismo extremo, el reconocimiento de que las explicaciones "funcionales" son incompletas si no se justifican en un esquema diacrónico y la aceptación de cierta carga de subjetividad en la formulación de hipótesis.

Pero al margen de las propuestas procesuales que enfatizan el cambio endógeno, existe un reducido grupo de investigadores, dentro del cual se encuentra Flannery, por ejemplo, más partidario de analizar el sistema en función, casi exclusivamente, de su adaptación al medio. Esto conduce, en casos extremos, a la llamada "ecología cultural", de moda en los años 70 -cuando el crecimiento demográfico, el deterioro medio-ambiental y el agotamiento de los recursos no renovables eran las principales preocu- 
paciones de la clase media americana (Schiffer 1.988: 467)-. Este análisis constituye un reduccionismo, en muchos casos mecanicista, en la explicación del cambio cultural. En general, estos autores defienden una visión materialista de la Historia, por lo que serán incluidos en el apartado de "materialismo vulgar".

\section{Aproximaciones materialistas}

Podrían clasificarse en dos grupos principales, si se excluyen la Teoría Crítica y el neo-marxismo por su reivindicación, en grados distintos, del relativismo:

I. Materialismo dialéctico o marxismo (Mundo occidental, Arqueología soviética y Arqueología social latinoamericana).

II. "Materialismo vulgar" (materialismo cultural y ecología cultural).

\section{Materialismo dialéctico o marxismo}

Como se sabe, Karl Marx diseñó un complejo modelo de las relaciones sociales y económicas que, tras elaboraciones de Engels a través del esquema evolutivo tripartito de Morgan (salvajismo, barbarie y civilización), ha servido de base para muchas interpretaciones del pasado.

El modelo se basa esencialmente, y de un modo quizás excesivamente esquemático, en la distinción de dos niveles estructurales dentro de la formación social: la infraestructura y la superestructura. Aquella puede identificarse con los factores socioeconómicos: los medios de producción, la fuerza del trabajo y las relaciones de producción, mientras que ésta consiste en todas las formas de "consciencia social". Pues bien: el peso causal que se otorgue a cada uno de ellos en la explicación de los procesos culturales determinará la adscripción de la interpretación a cada una de las corrientes nombradas.

El materialismo dialéctico se caracteriza, como su propio nombre indica, por el carácter conflictivo, dialéctico, que atribuye a los procesos históricos, cuyas transformaciones se producen, por tanto, como resultado de las contradicciones aparecidas entre ambos niveles estructurales. En palabras del propio Engels (1.890, cit. por Harris, 1.982: 182), "según la concepción materialista de la Historia, el factor que determina la Historia es, en última instancia, la producción y reproducción de la vida real. Ni Marx ni yo hemos afirmado nunca más que esto. Si alguien lo tergiversa diciendo que el factor económico es el único determinante, convertirá aquella tesis en una frase vacia, abstracta, absurda". Así pues, rechazan explícitamente los determinismos y mecanicismos que, sin embargo, caracterizaron los planteamientos oficiales en la Unión Soviética (Klejn, 1.971, 1.973, Semenov, 1.981).

Para esta tendencia, por tanto, la superestructura no es un mero epifenómeno de la infraestructura, sino que una vez establecida, puede influir en el desarrollo del proceso histórico (Kohl, 1.981: 109) por lo que deberán tenerse en cuenta en la explicación las circunstancias históricas particulares del proceso en estudio.

En su aplicación a la Arqueología, el materialismo dialéctico se caracteriza, lógicamente, por su énfasis en el análisis de jerarquías socio-políticas, tensiones entre clases, relaciones de poder, etc.. Sin embargo, debe afrontar fuertes críticas ante lo que, desde otras tendencias, se considera una extrapolación de los conflictos que caracterizan a la sociedad capitalista a otras donde no existe economía de mercado. Resulta problemático aplicar un análisis de clase a grupos definidos precisamente por la ausencia de éstas (Gilman, 1.974:116), por lo que diversos autores (Pearson, 1.984, Tilley, 1.984) sustituyen tales conceptos por otros más flexibles (como "grupos de interés" en lugar de "clase social", etc.). No obstante, estas argumentaciones siguen siendo criticadas (Trigger,R 1.989: 344), sobre la base 
de que asumen similares presupuestos, esto es, que siempre existen grupos de interés encontrado en una sociedad y, por tanto, conflicto social. Ello implica que todos los seres humanos están motivados por su propio interés y luchan por el poder, cuando otras interpretaciones del pensamiento marxista consideran, por el contrario, que la naturaleza humana es transformada de forma substancial por el cambio social, lo que justifica la lucha hasta alcanzar un futuro sin explotación. Por otra parte, critican el olvido de aquellos ejemplos etnográficos de sociedades de bajo nivel en que el prestigio se adquiere y se mantiene por medio de la redistribución y la generosidad, más que por el atesoramiento de riqueza. De hecho, estos críticos señalan que tanto Marx como Engels consideraban a las sociedades preclasistas como la prueba del carácter transitorio de las instituciones de las sociedades de clase, al no estar basadas en una naturaleza humana inmutablemente competitiva (Ibidem: 343).

Entre los representantes de esta tendencia en Arqueología occidental cabe destacar a Gilman y Kohl en EE.UU. Carandini y Tossi en Italia (donde se sigue una tendencia más fiel a la ortodoxia) y Randsborg y Kristiansen (con matices, pues su flexibilidad podría permitir calificarles de neo-marxistas) en Escandinavia. En España, los dos focos principales están constituídos por los departamentos de Prehistoria de la Universidad de Jaén (en donde investiga A. Ruiz:y anteriormente lo hacía F. Nocete, ahora en Huelva) y de la Universidad Autónoma de Barcelona, con V. Lull, cuyo nombre -"Departamento de Historia de las Formaciones Sociales Precapitalistas y Antropología Social"- es suficientemente explícito.

Por su parte, dentro del mundo latinoamericano se ha desarrollado una aplicación de los principios marxistas al estudio de la Arqueología que ha sido denominada "Arqueología social latinoamericana". Lo cierto es que constituye una tendencia singular, no sólo por los problemas que plantea, sino también por el compromiso social que su opción puede implicar, dadas las particulares circunstancias sociales de aquella realidad.

Las especiales características del mundo latinoamericano. con una gran población indígena sin acceso al poder y cuyos antepasados construyeron los monumentos y estructuras que ahora constituyen el objeto de estudio del arqueólogo, dota, sin duda, al mundo latinoamericano de unas especiales condiciones de conflicto que afectan incluso a la propia labor del investigador que, por esta causa, puede convertirse en instrumento real de lucha social.

Como señala Alcina (1.989: 94), es de destacar, además, lo que de renovador supone su actividad en unos países dominados bien por una arqueología tradicional con bases en la escuela histórico-cultural, o por una fuerte influencia de la Nueva Arqueología americana.

Esta orientación se inició en el $39^{\circ}$ Congreso Internacional de Americanistas, celebrado en Lima (Perú) en 1.970, siendo sus representantes más destacados L. Lumbreras, L.F. Bate, M. Sanoja, I. Vargas, O. Fonseca, J. Muntané, M. Veloz, etc..

II. "Materialismo vulgar" es el término ideado por Friedman (1.974) para denominar tanto al materialismo cultural norteamericano de M. Harris, como a la Antropología Ecológica de Vayda y Rappaport, ya que ambos comparten un excesivo reduccionismo y un absoluto mecanicismo en su concepción cultural, en la que la superestructura pasa a ser un mero epifenómeno, un simple reflejo, de la base infraestructural. A éste se otorga, por tanto, no sólo un peso determinante, sino exclusivo, en la configuración social.

La tecnología y el medio constituyen los únicos factores causales de la transformación cultural, aunque dependiendo de la importancia relativa que se conceda a cada uno de ellos en la explicación, se podrá clasificar a sus defensores en una u otra versión materialista vulgar. No obstante, debe quedar claro que son tenidos en cuenta ambos factores, ya que la adaptación al medio o el desequilibrio es 
siempre el argumento que explica la aparición de los conflictos internos. En España, A. Ramos Millán (1.981) defendió el materialismo cultural como modelo de explicación del inicio de la jerarquización social en el Sureste de la Península Ibérica durante el III Milenio.

\section{Arqueología Radical o Post-procesual}

Para dar contenido a este apartado, creo necesaria una aclaración ex initio sobre lo que yo entiendo por Arqueología Radical, dada la variedad de tendencias que se han incluído bajo este título general.

El término "radical" hace referencia a la reacción crítica en contra de la "raíz" de los planteamientos neo-positivistas de la N.A. y la Arqueología Procesual en los desarrollos teóricos de los años 80. Por la misma razón, todos estos enfoques han sido denominados post-procesuales. Ahora bien, desde esta perspectiva, también podría considerarse al materialismo histórico como un enfoque "radical", puesto que desde sus más básicos presupuestos, se muestra en abierta oposición al neo-positivismo. Sin embargo, no podría denominarse postprocesual si es que a este término se le otorga un contenido no sólo teórico, sino también cronológico (que no tendría por qué tener, pero que de hecho tiene), como algo desarrollado después y como reacción a la N.A., ya que el materialismo histórico constituyó una seria contrapartida a la N.A. desde los mismos comienzos de ésta. Por otra parte, muchos de los análisis realizados en Arqueología desde el materialismo histórico, tampoco se ajustarían al carácter de la Arqueología Radical y a su conciencia de la determinación histórica del conocimiento, por lo que he preferido tratarlo independientemente, aunque debe quedar claro este primer punto de duda.

En segundo lugar, a menudo se identifica Arqueología post-procesual con Arqueología Contextual o con el nombre de I. Hodder, cuando el término acoge también a otros enfoques, divididos esencialmente en dos tendencias:

- Los enfoques "marxistas" de la Teoría Crítica y el "neo-marxismo".

- Los enfoques "estructuralistas" de la Arqueología Estructural, la Arqueología Cognitiva y la Arqueología Contextual (o Arqueología Simbólica o Estructuralismo Simbólico).

- La Arqueología interpretativa.

Todos estos enfoque coinciden en oponerse a los fundamentos epistemológicos, teóricos y metodológicos de la N.A. (Preucel y Earle, 1.986: 2-3) que, a pesar de reclamar la reflexión y la discusión teórica en Arqueología, como bien señala J.M. Vicent (1.991) nunca elaboró una "Filosofía de la Arqueología", sino una "teoría de la Arqueología" en la que "las categorías abstractas del modelo de racionalidad científica del Positivismo Lógico reciben una interpretación operativa en términos de las condiciones específicas de la praxis arqueológica". Es decir: nunca se puso en cuestión el modelo de "única" ciencia posible, ni la viabilidad de otro método que el hipotético-deductivo, con lo que la única posibilidad de discusión giraba en torno de las distintas proposiciones relativas a la Arqueología.

Al rechazar tales presupuestos, y por tanto defender el relativismo epistemológico sin el único referente de racionalidad científica, los nuevos enfoques "radicales" abrían las posibilidades reales a la discusión teórica, lo que debería implicar la renovación absoluta de la disciplina. Ahora bien: este relativismo llevó a reivindicar, lógicamente, el principio de subjetividad, a partir del cual algunos autores radicales se encaminaron por la senda del subjetivismo, hasta llegar a situarse en una posición extrema. Pero este subjetivismo y relativismo extremos impiden la posibilidad de crítica y de construir una Arqueología basada en algún tipo de racionalidad, lo que inevitablemente conduce a un escepticismo frustrante sobre la accesibilidad al conocimiento del pasado prehistórico del hombre. Lo cierto es que únicamente la Arqueología Contextual asume de manera programática que "la motivación individual, resultado de valores históricamente estructurados, es el motor del cambio cultural", premisa que, 
sin embargo, es atribuida frecuentemente en la bibliografía (Preucel y Earle, 1.986: 3 en este caso, por ejemplo) a la Arqueología Radical o post-procesual en general. Sin embargo, debe admitirse que determinados representantes de otras tendencias (fundamentalmente neo-marxistas británicos) incurren en excesos relativistas comparables (v. infra), lo que puede justificar dichas extrapolaciones. Por tanto, resulta arriesgado incluir todas estas posiciones en un mismo apartado, pues cada una de ellas representa grados distintos de relativismo epistemológico, lo que a su vez implica otras diferencias.

Para conseguir, en la medida de lo posible, una más fácil comprensión de las distintas alternativas, y ya que he desarrollado previamente posiciones no-relativistas, en primer lugar haré referencia a los distintos enfoques radicales conforme a un orden creciente de subjetivismo y relativismo (pasando así del materialismo al idealismo). Comenzaré por la Teoría Crítica, la más vinculada al materialismo histórico y que escapa del relativismo extremo en que pueden incluirse representantes de las demás tendencias (aunque no todas las demás tendencias en sí, v. infra), para acabar con la Arqueología contextual. Sin embargo, terminaré el apartado con la última tendencia post-estructural propuesta desde Cambridge, la Arqueología interpretativa, que supone una crítica a los excesos subjetivistas previos pretendiendo asumir principios post-procesuales, procesuales y de la Teoría Crítica.

\section{La Teoría Critica $(T C)$}

Este término acoge una larga tradición de estudio iniciada en Europa cuando en 1.923 se crea en Frankfurt el Instituto de Investigación Social. La "Escuela de Frankfurt", entre cuyos miembros destaca Horkheimer, ha mantenido su línea de pensamiento hasta la actualidad, en que los escritos de Habermas, Marcuse o Adorno sirven de base a los nuevos "críticos", también denominados por algunos "para-marxistas" (Trigger, 1.989: 13; Hodder, 1.988: 195).

Sus defensores, que adoptan una perspectiva marxista de análisis histórico, aceptan que el conocimiento humano está históricamente determinado, aunque ello no implica la imposibilidad de crítica, como luego pretenderán los relativistas extremos.

En palabras de J.M. Vicent (1.991) 6 " "la Teoría Crítica sería, según Habermas, "la culminación de la reflexión de las categorías de la Razón Autónoma de la Ilustración sobre sí mismas, iniciada por las "críticas" kantianas. El conocimiento científico aparece ante ella como un producto social, cuyo sentido depende de su vinculación con intereses no cognoscitivos, sino pertenecientes a la esfera de la praxis social"“.

La TC desarrolla una "dialéctica negativa" que niega otro sentido a la práctica arqueológica que el derivado de las propias circunstancias en las que se desarrolla, y cuyo fin es desvelar la "falsa conciencia" que constituye dicha práctica (Ibidem). A juicio de este autor, "la Arqueología no tiene ningún sentido al margen de la noción ilustrada de Razón Autónoma" por lo que "la misma justificación de una está vinculada estrechamente con la defensa de la otra". En consecuencia, no cree posible una Arqueología posmoderna, si se identifica el movimiento posmoderno con la "desconstrucción" de la Ilustración.

Aceptando tal premisa, la TC se plantea, como objetivo principal, analizar la "falsa conciencia" "interpuesta por los arqueólogos entre su percepción de la actividad que realizan y los verdaderos compromisos de esta con la realidad" (Ibidem), lo que constituye el punto de análisis crucial y que, precisamente por ello, no ha sido abordado aún por ninguno de los planteamientos pretendidamente

6. A quien agradezco el haberme permitido manejar este texto, aún inédito. 
"radicales". Estos se han limitado, a su juicio, a elaborar nuevas "teorías de la Arqueología" sin alcanzar, tampoco una auténtica "Filosofía de la Arqueología".

En este sentido, los comúnmente considerados y auto-denominados enfoques "radicales" no serían tales, puesto que no someterían la disciplina a una crítica tal, dejando sin desvelar, en consecuencia, las relaciones entre conocimiento e interés, lo que resulta de capital importancia para valorar el futuro de la Arqueología (Ibidem).

\section{Neo-marxismo}

Schiffer (1.988: 467) definió el neo-marxismo como "algo que participa de ideas marxistas filtradas a través de la sociología y la antropología social francesa (y a veces británica) introducido recientemente en la arqueología británica y americana" (ej. Friedman y Rowlands 1.978, Miller y Tilley 1.984, Spriggs 1.984).

En efecto, el neo-marxismo, denominado también "marxismo decadente" por Johnson y Earle (1.987), surge del marxismo estructural representado por filósofos como Althusser o Bettelheim y representado a su vez en Antropología por Godelier o Marshall Sahlins. Esta tendencia deriva, en principio (Preucel y Earle, 1.986: 2) de una parte, de los escritos de Marx, cercanamente ligada a sus actividades políticas, según la cual, la posibilidad de cambio creativo es esencial para hacer posible la revolución. Considera que el comportamiento humano sólo es comprensible dentro de contextos culturales específicos, en los que la motivación humana deriva de la "estructuración" social de la realidad.

Sobre estos principios han construido sus argumentaciones arqueólogos como Tilley (1.981), Shennan (1.982) -referida además al Sureste español- Miller y Tilley (1.984), Shanks y Tilley (1.982), etc..

$\mathrm{Al}$ igual que los demás enfoques marxistas, la contradicción y el conflicto son fundamentales para comprender el proceso cultural; pero a diferencia de ellos, la superestructura, la ideología, juega para ellos un papel primordial como agente causal de tales contradicciones: la ideología es un factor activo en las relaciones sociales, en la construcción de la realidad, situándose, por tanto, en el extremo opuesto al "materialismo vulgar".

A veces, este poder de la ideología se contempla dentro de un marco de análisis materialista (por ello algunos trabajos de Kristiansen podrían incluirse aquí), pero muchas más se ajusta a un evidente idealismo (Miller y Tilley, 1.984; Parker Pearson, 1.984) que lleva al último de estos autores, por ejemplo, a defender (1.984: 61), sin ninguna mención a su función económica, que los útiles son productos de la ideología en el mismo grado que un código civil o una corona (Trigger, 1.989: 341).

Pero no sólo existen desacuerdos a este respecto. Tampoco coinciden, por ejemplo, en el grado en que deben conocerse las ideologías prehistóricas para poder establecer el papel que jugaron en sus respectivas sociedades, o en la valoración que les merece el peso de la ideología actual en nuestra visión del pasado (Ibidem: 342-5). Porque, de hecho, del análisis de la ideología y de su importancia en la configuración cultural se deriva un variable convencimiento de que constituye un instrumento más de poder en manos de la clase dominante (v. supra críticas a la inmutabilidad de la naturaleza humana). Ello conduce a una posición relativista, cuyas raíces se retrotraen hasta las primeras formulaciones de la TC, que profundiza en la interferencia de la ideología actual en la labor del arqueólogo, y que lleva a sus representantes más extremos (Miller y Tilley, 1.984 por ejemplo), a poner en tela de juicio la posibilidad de conocimiento del pasado, defendiendo que las diversas interpretaciones únicamente deben juzgarse en función de su coherencia interna. Analizaremos las últimas derivaciones (Shanks y Tilley, 1.987a y b) de estas posiciones iniciales al tratar de la Arqueología post-moderna. 


\section{Las Arqueologías estructuralistas}

Abandonando ya cualquier matiz materialista y por tanto cualquier punto de conexión con la NA y la Arqueología Procesual, a la que se opone visceralmente, se encuentra la Arqueología Contextual, corriente liderada por el británico I. Hodder.

La Arqueología Contextual fue, durante un tiempo, la más importante aplicación en Arqueología de la tradición estructuralista, cuyo principal exponente es, como se sabe el antropólogo francés LeviStrauss. Esa defiende, de una manera esquemática, que la mente humana está regulada, a nivel incosciente, por una serie de estructuras que se manifiestan en las actividades conscientes y que, por tanto, quedarán reflejadas en las manifestaciones materiales. Así, los objetos arqueológicos se convierten en símbolos de las estructuras inconscientes de la mente, o lo que es lo mismo, en significantes para un significado que se intenta conocer.

En la actualidad, pueden diferenciarse tres enfoques derivados de esta misma base: la arqueología estructural propiamente dicha -cuyo más conocido representante fue A. Leroi-Gourhan-, la cognitiva y la simbólica. P.J. Watson (y Fotiadis 1.990) nos servirá de base para su análisis:

Los tres coinciden en considerar la cultura material como un "texto" (en el sentido de Derrida), un conjunto de símbolos codificados con las leyes que organizaron la vida de las gentes que la creó. Sin embargo, la arqueología estructural y la simbólica están mucho más interesadas por la cualidad interactiva de la cultura -la interacción entre grupos sociales y sistemas simbólicos- que la cognitiva. Algunos arqueólogos estructuralistas difieren de los simbólicos en dotar a los sistemas simbólicos de una configuración binaria, basada en conjuntos coherentes de oposiciones fundamentales (masculino/femenino, puro/impuro, sagrado/profano, etc.) y, en general, apliquen el análisis binario o no, los estructuralistas no están interesados en conocer el origen de estos sistemas simbólicos, cuestión que sí preocupa a los arqueólogos simbólicos. Por su parte, los cognitivos, cuyo fin es encontrar las pautas cognitivas que, a su juicio, se codifican en la cultura material, usan a veces oposiciones binarias según el método de Lévi-Strauss, pero no están interesados ni en la cualidad interactiva de la cultura, ni en los orígenes, ni en el contexto histórico, socio-cultural o la importancia que para los individuos pudieran tener esos sistemas simbólicos que describen. Sólo pretenden conocerlos en sí mismos. Ahora bien, eso les lleva a compartir con los simbólicos una profunda atención al "significado intracultural" (intentar adoptar el punto de vista de los nativos que protagonizan/zaron la cultura en estudio), ya que persiguen más la interpretación que la formulación de explicaciones científicas, como antes hacía la NA. Entre ellas, la Arqueología estructural sirve de base, en la actualidad, a los trabajos de F. Criado Boado (1.989, $1.989 \mathrm{~b}, 1.990)$.

Pero ha sido la llamada Arqueología contextual (también denominada Arqueología simbólica o estructuralismo simbólico) ${ }^{7}$ la que posiblemente más ha llamado la atención entre las "derivaciones" estructuralistas. Sin duda dos factores han contribuído a ello: la plataforma desde la que partió, la Universidad de Cambridge, y el éxito personal de su principal representante, I. Hodder. De hecho, el relativismo y el subjetivismo extremo que la definen, se han extrapolado en la bibliografía como característica general de las posiciones post-procesuales. Esa es la razón por la que centraremos en ella el estudio.

I. Hodder, que durante los años 70 había trabajado en Arqueología Espacial (Hodder y Orton, 1.976), inició una nueva trayectoria profesional tras realizar trabajos etnográficos en el lago Baringo (al Oeste de Kenya) donde descubrió que la cultura material está llena de simbolismo, y por tanto,

7. Desde este punto de vista aborda I.G. Lisboa (1985) una cuestión referente al Calcolítico español. 
significativamente constituida (Hodder, 1.979). La primera consecuencia de tal apreciación es, lógicamente, que la cultura material deja de ser considerada como un mero reflejo de la adaptación ecológica o la organización socio-política, tal como propone la NA, para convertirse en un elemento activo en la interacción social, que puede utilizarse tanto para enfatizar, como para enmascarar una determinada ideología (Trigger, 1.989: 348).

Ahora bien: si los restos materiales pueden, a través de su simbolismo, utilizarse con fines opuestos dentro de un grupo social, será imposible conocer su significado y, por tanto, esa organización social, a menos que examinemos todos los demás aspectos del registro arqueológico. Esto es: necesitamos conocer todos los componentes de cada cultura arqueológica, todo el contexto, para poder comprender el significado de cada una de las partes (Ibidem: 348-50). Así, por ejemplo, los enterramientos pueden carecer de signos de diferenciación, representando una realidad social sin desigualdades intergrupales, cuando el análisis del asentamiento revela lo contrario, de lo que debe deducirse un intento de enmascarar la ideología prevalente y cómo ésta utilizó los enterramientos de forma simbólica. Lógicamente, con tal perspectiva, niega validez a todos aquellos trabajos donde se analizan aspectos particulares de la cultura, parcelas de su totalidad, lo que incluye los resultados de las llamadas Arqueologías de Alcance Medio, desarrolladas por la NA (Arqueología Funeraria, Arqueología Social) en donde sólo se tienen en cuenta algunas variables.

La Arqueología contextual reclama, así, la importancia del individuo en la elaboración de la Historia, al defender que la interacción de la cultura material y la sociedad es particular para cada grupo humano. Sólo podrá "comprenderse" la cultura adoptando su punto de vista interno, por lo que no existe explicación en Arqueología, sino sólo interpretación. Ahora bien, a partir de ello, trasladan el razonamiento al presente, y con ello al arqueólogo, señalando que éste no puede escapar al presente en su visión del pasado. De eso se sigue que los datos arqueológicos son interpretaciones dadas, basadas en nociones actuales que, en sí mismas, influyen la teoría que, se supone, debe ser probada, por lo que, consecuentemente, no hay posibilidades de verificación científica (Preucel y Earle, 1.986: 2). La cadena acaba en la afirmación de Hodder (1.984: 30) de que "no existen bases externas, objetivas, para decir que cualquier teoría que sea coherente, esté bien argumentada y se «ajuste» a los datos, sea mejor que cualquier otra que esté bien argumentada, pero basada en asunciones distintas". En resumen, ello supone afirmar que, puesto que todas las teorías y explicaciones son productos culturales y no hay realidad objetiva contra la que probarlas, los preceptos y procedimientos de la ciencia son inapropiados para la Arqueología. El punto de llegada es la "seria crisis escéptica" que P.J. Watson (y Fotiadis 1.990: 621) atribuye a I. Hodder, o la consideración de la Arqueología como un simple ejercicio literario a la que parecen adscribirse algunos de sus seguidores.

Pero la Arqueología contextual es sólo una de las corrientes que podrían incluírse en la denominada por Hodder (1.987), arqueología post-moderna, a la que a su vez, suele identificarse en la profesión con la Arqueología post-procesual y a la que Renfrew (1.990:34) prefiere denominar anti-procesual (¿me sigue alguien a estas alturas, o no sólo no he impedido, sino que he provocado la huida?). Esta incluye variadas líneas de fuerza ${ }^{8}$ (Arqueología Contextual, feminista, no-académica, del Tercer Mundo, etc.), que no intentan ya conocer la realidad -recordemos que, a su juicio, tal objetivo es fútil-, sino ofrecer

8. En el sentido de que no constituyen corrientes o tendencias cerradas y distintas, sino líneas, a menudo convergentes, de un mismo pensamiento derivado, como todo el post-procesualismo inglés, de una mezcla (?) de hermeneútica y estructuralismo. Casi podría decirse que se trata de una cuestión de énfasis, que puede ser circunstancial incluso en un mismo autor, que de esta forma, parece, erróneamente, representar posturas distintas, según el texto que de él se maneje. Debo señalar a este respecto la dificultad que entraña, al menos para mí, sistematizar las posiciones actuales del pensamiento británico en Arqueología, dada, precisamente, la falta de sistematización en su desarrollo. 
visiones particulares del pasado -dadas las circunstancias particulares de cada arqueólogo y su proyección al pasado de las mismas- (Ruiz, Chapa y Ruiz, 1.988: 14).

No cabe duda de que la Arqueología Contextual ha contribuido de una manera importante al conocimiento del pasado al demostrar el papel activo que tiene la cultura material en la configuración cultural. Pero ha recibido numerosas críticas (Preucel y Earle, 1.986, Schiffer, 1.988, Ruiz, Chapa y Ruiz, 1.988, Kohl, 1.985, Watson y Fotiadis, 1.990, ETC.). La primera de ellas se dirige exactamente hacia todo aquello que intente sobrepasar tal pronunciamiento: la semiótica ha establecido claramente que la relación entre el significante y el significado dentro de un sistema cualquiera de expresión, es arbitraria. Al signo se atribuye un significado que puede variar dependiendo de las culturas, al tiempo que los mismos significados se simbolizan en signos distintos. Del mismo modo puede decirse (Gallay, 1.986: 197) que la relación entre la cultura material y su significado simbólico puede ser, esencialmente arbitraria. Así pues, ¿cómo puede determinarse en los estudios contextuales sobre la Prehistoria si la relación entre ambas es directa, inversa, contradictoria, etc.? ¿Cómo se puede reconstruir el significado? Trigger (1.989: 351) señala que, "hasta ahora, ningún arqueólogo ha descubierto cómo evitar la especulación al interpretar el significado cultural de" las regularidades en el registro arqueológico "de la Prehistoria", además de que, en cualquier caso, según Gallay (1.986: 198-200 y 281), no hay forma de "demostrar una relación isométrica entre nuestras ideas sobe el pasado y las ideas que realmente la gente mantenía en el pasado" (Trigger, ibidem). Evidentemente, ésta será una de las principales causas por las que los arqueólogos contextuales dirigen su atención especialmente al estudio de culturas con registros escritos o a la Etnoarqueología, en lugar de prestar atención a la Prehistoria.

En general, los críticos coinciden en denunciar una "falta de cuerpo teórico donde sean demarcadas las cuestiones epistemológicas, las estrategias metodológicas, los objetivos y hasta el propio planteamiento de veracidad, de un modo no ya criticable desde otro paradigma, sino desde el propio de la Arqueología Contextual" (Ruiz, Chapa y Ruiz, 1.988: 14). Todo ello se manifiesta, a su juicio, en los resultados de sus trabajos, definidos por los autores citados por una "arqueología de ejemplos" y la imposibilidad de analizar contextos prehistóricos (Ibidem; Trigger, 1.989: 351-4; Watson y. Fotiadis, 1.990: 621). Debe señalarse que el lúcido trabajo de Gibbon (1.989) puede sentar las bases de una nueva trayectoria en este sentido, al dotar a la arqueología post-procesual de dicha base teórica.

Un último grupo de autores basa su crítica en juzgar que, de las premisas que asumen, cabría deducir A) que los relativistas extremos aceptarían como válida toda interpretación coherente (v. supra Hodder, 1.984: 30), independientemente de su inspiración teórica, no siendo este el caso (Schiffer, 1.988: 468; Chippindale, 1.990: 465) y B) deberían aplicar el mismo relativismo para juzgar, en el presente, el devenir de la Ciencia, cuestión que también parece contradictoria con sus argumentos (Ruiz, Chapa y Ruiz, 1.988: 13).

Lo cierto es que entre los radicales se llegaron a adoptar posturas criticadas incluso entre ellos mismos (por ejemplo Rowlands 1.984), que han representado el extremo idealista opuesto en la oscilación teórica, a los más estrictos planteamientos materialistas para los que el individuo era sólo un instrumento pasivo al servicio de la Historia.

Entre los últimos y más destacados representantes de la Arqueología post-procesual puede contarse a M. Shanks y C. Tilley, cuyas dos últimas obras (1.987a y b) han sido objeto de generalizada atención (v. Shanks y Tilley, 1.989). En ellas, pretenden defender un "pluralismo radical" y prestan especial atención a cuatro corrientes actuales de pensamiento (Ibidem:10): hermeneútica, estructuralismo y post-estructuralismo, Teoría Crítica y materialismo dialéctico. No creen deseable una teoría unificada que integre esas diferentes tendencias, ya que representaría, necesariamente, un acto reduccionista y esencialista. Por el contrario, el objetivo debe ser un sistema abierto de referencias que permita 
desarrollar una arqueología social madura y auto-reflexiva. Sólo así podrá alcanzarse, a su juicio, un "genuino pluralismo" (Ibidem), distinto al actual, que "sólo es tolerạdo mientras no suponga una auténtica oposición que no pueda ser neutralizada (en una diversidad de perspectivas igualmente «verdaderas») o contenida de alguna otra manera“ (Ibidem:11). La meta final debe ser (Ibidem:9) "establecer una socio-política diferente de la arqueología“, pues ya que ésta no es autónoma de la sociedad, los efectos de su discurso impregnan y afectan a toda la producción cultural (Ibidem:11). Es por ello que el significado del pasado no pertenece al pasado, sino al presente y que la arqueología "no es tanto una lectura de los signos del pasado, cuanto un proceso en el que estos signos se escriben en el presente" (Ibidem:4).

El artículo de Shanks y Tilley va acompañado de extensos y lúcidos comentarios de otros autores, que sirven de claros denotadores de la situación actual de la arqueología en el mundo inglés. Porque dos comentarios llaman poderosamente la atención: por un lado, el de Renfrew, brillante clarificación de términos y presupuestos en su defensa de la arqueología procesual. Y por otro, el de I. Hodder.

Resulta curioso que sea precisamente este autor quien critique a Shanks y Tilley (Hooder, 1.989:15) su incapacidad para abordar en términos verdaderamente dialécticos el análisis de las principales cuestiones del debate -la oposición presente/pasado, teoría/datos, etc.- y quien señale (Ibidem:17) que, "en realidad, producir un pasado plural y polisémico es presagiar la pérdida de la autoridad arqueológica (...) y de cualquier capacidad para hablar sobre el pasado".

Tan aparente cambio de actitud responde a la asunción de los presupuestos de la arqueología interpretativa, última corriente teórica abanderada por I. Hodder (1.991).

La arqueología interpretativa pretende superar las carencias demostradas tanto por la arqueología procesual como por la post-procesual. Esas se refieren, fundamentalmente, a la falta de sensibilidad para la interpretación de los significados históricos internos y específicos y a la despreocupación por el contexto social e ideológico del arqueólogo (Ibidem:8). Hodder considera ahora que la anterior arqueología post-procesual argumentaba en realidd sobre el presente, no sobre el pasado, y que criticando a las demás alternativas practicaban muy escasa autocrítica: "Tan radical como (...) pretendía ser", en realidad "tendía a hacer lo mismo" que la arqueología procesual "de diferente forma" (Ibidem).

Propone un nuevo modelo que incorpore los logros obtenidos por otras tendencias. Estaría basado en tres premisas fundamentales: 1) El reconocimiento de la existencia de cierta objetividad del pasado, lo que significa que los "datos" se forman en una relación dialéctica. Tal asunción es la única vía para que grupos no académicos o institucionales de arqueólogos puedan desarrollar, con posibilidades competitivas reales, hipótesis alternativas de explicación (Ibidem:10 y 15). Ello deriva en un interés técnico o instrumental y se corresponde con lo que "la mayoría de los arqueólogos americanos identifican como «ciencia» en la arqueología procesual, ecológica, evolucionista, (...), positivista"(Ibidem:13).

2) Es necesario comprender al Otro en sus propios términos, para lo que parece imprescindible un componente hermeneútico en la interpretación (Ibidem:10-15). Ello contribuirá a dotar al pasado de una "escala humana", sacándole del encierro en una ciencia o teoría distante y abstracta al que ahora le sometemos. De esta manera, puede decirse que interpretar es actuar, porque la interpretación trae el pasado a debate público (Ibidem:15).

3) Debe incorporarse la auto-crítica y el diálogo con otras posiciones. Para ello la Teoría Crítica, ya reclamada por Shanks y Tilley (v.supra) puede ser de gran utilidad.

En resumen podría decirse que la arqueología interpretativa "construye narrativas o cuenta historias”. Pero historias en las que se admite el poder e influencia de su retórica, que están hechas a escala humana, que no excluyen el punto de vista de los autores y donde está presente el narrador para posibilitar la crítica (Ibidem:13). 
En la actualidad estamos contemplando, pues, la aparición de posturas más eclécticas, que comparten el reconocimiento del peso de la ideología en la elaboración del pasado y la importancia del registro arqueológico como único referente objetivo de las propuestas para su reconstrucción. Así, al tiempo que I. Hodder reconoce la aportación positivista y procesual de "una "objetividad" del material del "Otro" que ofrece la bases para una crítica a través de la realidad de la diferencia" (Hodder, 1.991:12), C. Renfrew (1.989:38) manifiesta que "hoy nadie pretende que los datos puedan, en un sentido absoluto ser "objetivos". No son formulados más que por la actividad humana y no son independientes de ese proceso".

La realidad es que ya casi nadie duda hoy del peso de la ideología pasada y presente en la elaboración del pasado (por parte de sus creadores y por parte de sus investigadores). Quizás haya sido esta la principal aportación de aquellas posiciones subjetivistas extremas, que contribuyeron así, a equilibrar la balanza materialista/idealista, objetivismo/subjetivismo en la mayor parte de las tendencias actuales (v. Trigger, 1.989: 368-9)

\section{EL FUTURO}

Resulta complejo analizar este punto. A mi juicio es necesario, para empezar, diferenciar varios niveles sobre los que desarrollar la cuestión.

En primer lugar, debemos volver a la Introducción y recordar aquel concepto de Teoría que no se ha contemplado aquí. Desde este punto de vista, sería de desear una verdadera reflexión, crítica, sobre nuestra propia actividad, objetivo planteado por la Teoría Crítica y como tal, asumido por la arqueología interpretativa, aunque aún no desarrollado ${ }^{9}$. De ello dependerá, en efecto, la posibilidad de "autonomía gnoseológica" y su "viabilidad como empresa de conocimiento racional" (Vicent, 1.991).

Dentro de este mismo nivel de autocrítica, cabría situar la reflexión sobre arqueología e indigenismo en aquellos países donde se produce tal hecho. La Arqueología radical abrió aquí un amplio campo de debate que, previsiblemente, habrá de continuar, pues se incluye, como la ecología o el deterioro del medio ambiente en general, en el área de los "problemas permitidos" de la sociedad actual. No hay más que recordar el éxito comercial (del que son buena prueba sus 7 Oscars) de la película "Bailando con lobos", dedicada a ensalzar los valores culturales y humanos de los indios Sioux (a pesar de un cierto trasfondo racista: el protagonista, bueno y sabio sigue siendo, al fín y al cabo, un blanco). A este respecto, me parece interesante resaltar la duda de Trigger (1.990: 781) sobre si la nueva aceptación de los valores indígenas en la sociedad actual refleja el impacto de los datos arqueológicos o simplemente el "menos arriesgado y más romántico estereotipo de indios que se desarrolló en la cultura Euroamericana" una vez que estaba clara su dominación. A mi juicio, ésta puede ser, precisamente, la razón de que la Arqueología británica y americana analicen la cuestión desde perspectivas distintas a la desarrollada por aquellos países donde todavía hoy la mermada población indígena puede seguir constituyendo una amenaza para el sistema (v. Mamami Condori, 1.986 y Males, 1.986 , por ejemplo) ${ }^{10}$.

9. En este sentido, me parece de vital importancia el inicio de la aplicación de la TC a la Arqueología, en los términos en que lo hace J.M. Vicent (1991), la actitud crítica que manifiestan los trabajos de F. Criado (1988b, 1989b, por ejemplo) y la "Convocatoria para una reunión de Arqueología Teórica", a celebrar, en principio, en 1992, firmada por F. Criado, F. Nocete y J. Vicent.

10. Quizás por ello, previsiblemente, la arqueología interpretativa sólo se desarrolle en el mundo anglosajón o plenamente occidental. La incorporación del punto de vista del Otro resulta problemática cuando el Otro amenaza la posición del investigador. 
En segundo lugar, y relacionado, al menos en uno de los niveles desde donde se puede abordar, con la cuestión precedente, una de las preocupaciones que se revelan prioritarias en el futuro es la dilucidación de la existencia de la disyuntiva arqueología de investigación/arqueología de gestión. Este nivel es el que introduce la arqueología en general en la más amplia disyuntiva Ciencia/Técnica, o lo que es lo mismo, en la necesidad de decidir si existe autonomía de conocimiento para la Arqueología -Ciencia- o no -Técnica-. De resolverse negativamente, toda actividad arqueológica -de "investigación" o de "gestión"-, resultará esencialmente idéntica, pues "en la medida en que el arqueólogo integrado bien en el mercado de productos culturales de consumo, bien en la práctica de una gestión política de los recursos culturales, sólo puede desempeñarse como técnico (en el sentido de -Max Weber) -es contratado para resolver un problema concreto a gusto de su cliente, sea éste el Estado o un particular-", como comienza a suceder con ritmo acelerado en la sociedad actual, "la finalidad de su trabajo queda comprometida, al margen de que el profesional se perciba a sí mismo como un científico" (Vicent, 1.991).

Pero hay otro nivel de análisis que ya está siendo abordado (Criado, 1.988; Ruiz Rodríguez, 1.989; Martínez Navarrete, 1.990; Ruiz Zapatero, 1.991; Ruiz, Hornos y Molinos, e.p.; etc.) que equipara dicha disyuntiva con la de investigación/conservación, pretendiendo muchos superarla bajo la propuesta "investigar para conservar y conservar para investigar" (Ruiz, 1.989: 15).

En tercer lugar, y en el nivel de las "teorías en Arqueología" en que nos venimos moviendo en este trabajo, podría decirse que la tendencia general mantiene la disyuntiva básica: por un lado, posiciones realistas y por otro, instrumentalistas; por uno materialistas y por otro, idealistas; por uno procesuales y por otro post/anti-procesuales.

Entre las primeras se incluye la pervivencia de la Nueva Arqueología, activa y muy presente en gran parte del mundo, otras formas de arqueología procesual (funcionalista-procesual y cognitiva-procesual) y las arqueologías materialistas. Todas ellas consideran que "el pasado realmente ocurrió". Muchos de sus defensores no dudan de que el pasado sea construído por nosotros en el presente, pero consideran que los criterios de validación de su reconstrucción no derivan de su utilidad -política, social, ideológica- en el presente, sino de la evidencia empírica del registro arqueológico (Renfrew, 1.989:40). Ponen el énfasis en la comprensión de las regularidades inter-culturales, considerando, en consecuencia las ideologías, creencias y tradiciones como parte del contexto en el que actúan las condiciones sociales y económicas, que establecen las bases del cambio para unos, o que interactuan con aquellas para provocarlo, según otros (Trigger, 1.989: 368).

Renfrew (1.989:39-40) preve para los años 90 el desarrollo de la arqueología procesual-cognitiva, flexibilización, como veíamos, de los principios procesuales, que incluye varias premisas compartidas (o propuestas) por los post-procesuales: rechazo del método nomológico-deductivo de Hempel, adopción de un método científico distinto al de las Ciencias Naturales, rechazo a un positivismo extremo, reconocimiento de la subjetividad del investigador al formular hipótesis y precaución con la circularidad potencial de conceptos evolucionistas como "adaptación" o "idoneidad".

Por su parte, la segunda gran tendencia o alternativa acoge todo tipo de arqueología post/antiprocesual, incluyendo, claro, la interpretativa. Desde aquí se considera que "una posición crítica reconoce que contar historias basadas en datos depende de las relaciones de producción del conocimieto arqueológico" (Hodder, 1.991:16), por lo que éstas siguen constituyendo uno de los criterios de validación de la reconstrucción del pasado.

Dentro de este segundo grupo, parecen advertirse, de nuevo, tres líneas de fuerza " fundamentales: por un lado, una continuación de las preocupaciones que definieron la Arqueología post-procesual de

11. V. supra nota 8. 
los años 80, a juzgar por el tipo de temas que protagonizaron la III sesión del TAG (Theoretical Archaeology Group), celebrada en Lampeter en Diciembre de 1.990: Arqueología feminista, tradición e identidad cultural, uso simbólico del espacio y la arqueología, la influencia de la emoción en la Arqueología, etc ${ }^{12}$.. La Arqueología feminista mantiene y refuerza la atención, sirviendo de crítica a su vez a otras posiciones post-modernas (Ibidem:9).

Por otro, un énfasis en la utilización de la semiótica para el análisis del pasado. Desde este punto de vista, el registro arqueológico se identifica con un "texto" que hay que descifrar, acudiéndose para ello a estudios sobre Filosofía y Linguística estructuralista (del tipo J. Derrida o M. Foucault) (Bapty y Yates, 1.990).

Y por último, un desarrollo de la arqueología interpretativa que, como vimos y de acuerdo a la descripción de Shanks, "intentará, de forma general, ajustarse a los datos, seguir la evidencia real de un pasado que realmente existió", "explicará los mundos pasados en términos de como vemos nosotros nuestros propios mundos presentes" y, por último, "intentará ser retórica, esto es, realizar su trabajo con algún grado de gracia y estilo" (Chippindale, 1.990:465).

Para terminar, en el nivel de los previsibles desarrollos de la técnica aplicada a la Arqueología, cabe destacar el de la Informática y los sistemas expertos de Inteligencia Artificial para el estudio del pasado ${ }^{13}$ : por una parte, Francia, como reacción a las influencias anglófonas, está empezando a desarrollar lo que sus creadores (A. Gallay y J.Cl. Gardin) califican "de reflexión sobre la naturaleza epistemológica de la Arqueología" (Gallay, 1.989: 28) y que ha recibido el nombre de "Logicismo". Reclamando de nuevo el tan vilipendiado positivismo, consiste en un "análisis de los constructos arqueológicos, o más simplemente, de las publicaciones arqueológicas. En consecuencia, el logicismo no hace referencia en primera instancia al menos, a los restos arqueológicos en sí mismos, sino a lo que los arqueólogos dicen de ellos" (Ibidem). Para ello esquematiza el razonamiento arqueológico de un modo similar al de los sistemas expertos, intentando "revelar los fundamentos de las interpretaciones propuestas, además de sus defectos", con lo que hacen aparentes otras pautas de razonamiento (Ibidem: 32-33).

Por otra parte, en Gran bretaña se está realizando, aunque desde presupuestos teóricos contrarios (Stutt y Shernnan, 1.990), investigaciones encaminadas a conseguir un programa de Inteligencia Artificial de ayuda al arqueólogo para la producción y evaluación de argumentos. Para ello se parte de analizar la naturaleza de éstos, dentro también del interés por la Lingüística post-estructural.

En conclusión, en el futuro parece perfilarse un mayor nivel de exigencia auto-crítica, tanto en las posiciones procesuales como en las post/anti-procesuales, lo que sin duda conducirá a un mayor nivel de conciencia sobre la responsabilidad social de nuestro trabajo. Por otro lado, la ampliación y perfeccionamiento de técnicas y métodos para la recuperación y tratamiento del registro arqueológico parece constituir, también, punto de encuentro de los futuros desarrollos de la disciplina. Pero, en cualquier caso, la alternativa de estudio seguirá tan claramente definida como hasta ahora, dilucidándose a través del interés en lo general o en lo particular, del énfasis en lo objetivo o en lo subjetivo, de la carga de realidad específica que se conceda al Otro ${ }^{14}$.

12. Agradezco a M.I. Martínez Navarrete el haber tenido acceso al resumen del programa de dicha reunión.

13. Es de destacar en este sentido, el éxito de participación que registró el Congreso sobre Aplicaciones Informáticas en Arqueología, organizado por V. Fernández y G. Fernández en el Dpto. de Prehistoria de la Universidad Complutense de Madrid durante el mes de octubre de 1990. (FERNANDEZ MARTINEZ, V. y FERNANDEZ LOPEZ, G. e.p.).

14. Debo agradecer a J.M. Vicent y a F. Criado sus clarificadores comentarios a cualquiera de mis consultas. A G. Politis la lectura detenida y crítica del texto y sus oportunas y acertadas reflexiones. No haberlo sabido mejorar más es, por supuesto, de mi única responsabilidad. 


\section{BIBLIOGRAFIA}

ALCINA FRANCH J. (1.989): Arqueología Antropológica. Akal Universitaria, Serie Arqueología. Madrid.

ALONSO DEL REAL, C. (1.987): Prólogo en J.M. Bello, F. Criado y J.M. Vázquez Varela (1.987): La cultura megalítica de la provincia de La Coruña y sus relaciones con el marco natural: implicaciones socioeconómicas. Excma. Diputación Provincial de

La Coruña. La Coruña, pp. 13-14.

ARNOLD, B. (1.990): The past as propaganda: totalitarian archaeology in Nazi Germany. Antiquity 64:464-78.

BAPTY, I y YATES, T. (Eds.) (1.990): Archaeology after Structuralism. Routledge, London.

BINFORD, L.R. (1.962): Archaeology as Anthropology. American Antiquity 28 (2): 217-225.

- : (1.965): "Archaeological systematics and the study of culture process". American Antiquity, 31: 203-210.

: (1.968): Archaeological perspectives. En S.R. Binford y L.R. Binford (eds.): New Perspectives in Archaeology. Aldine, Chicago, pp 5-32.

CHIPPINDALE, C. (1.990): Theoretical Archaeological Group: Ind Conference. Current Arthopology, 31 (4): 463-466.

CLARKE, D. (1.968): Analytical Archaeology. Methuen, London (Arqueología Analítica, Bellaterra, S.A. Barcelona, 1.984). : (1.973) Archaeology: a loss of innocence. Antiquity 57: 6-18.

CRIADO BOADO, F. (1.988): ¿Qué es un arqueólogo? ¿Qué es la Arqueología? Revista de Arqueología, 82: 5-7.

peninsular y su medio natural: implicaciones socio-económicas. Universidad de Santiago: Tesis doctoral presentada en la Facultad de Geografía e Historia. Inédito.

— : (1.989): Megalitos, espacio, pensamiento. Trabajos de Prehistoria 46: 75-98.

— : (1.989b): El passat segons el poder: alternatius, policies i arqueólegs a Stonehenge. Cota Zero 5: 109-114.

- (1.990): Arqueología del paisaje en Galicia. Arqueolgía Espacial. Lisboa-Tomar, 10-13 Marzo, 1.988. Teruel 61-117.

CRIADO, F., NOCETE, F. y VICENT, J. (1.991): Convocatoria para una reunión de Arqueología Teórica. Texto publicado en Revista de Arqueología 120, Abril 1.991.pp. 63-64

FERNANDEZ MARTINEZ, V. (1.989): Teoría y metodología de la Arqueología. Historia Universal I. Prehistoria. Ed. Sístesis. Madrid.

FERNANDEZ MARTINEZ, V. y FERNANDEZ LOPEZ, G. (coord.) (e.p.): Aplicaciones Informáticas en Arqueología. Complutum.

FLANNERY, K.V. (1.973): Archaeology with a capital S. En Ch.L. Redman (ed.): Research an theory in current archaeology, Wiley, New York, pp. 47-58.

FRIEDMAN, J. (1.974): Marxism, Structuralism and vulgar materialism. Man 9 (3): 444-469.

FRIEDMAN, J. y ROWLANDS M.J. (1.978): Notes toward an epigenetic model of evolution of civilisation. En J. Friedman y M.J. Rowlands (Eds.): the evolution of social systems. Duckworth, London, pp. 201-279.

FRITZ, J.M. y PLOG, F.T. (1.970): The nature of archaeological explanation. American Antiquity 35:405-412.

GALLAY, A. (1.986): L'Arquéologie demain. Belfond, Paris

: (1.989): Logicism: a french view of archaeological theory founded in computational perspective. Antiquity 63: 27-39.

GIBBON, G. (1.989): Explanation in archaeology. Basil Blackwell, Oxford.

HARRIS, M. (1.979): El desarrollo de la teoría antropológica. Una historia de las teorías de la cultura. Siglo XXI, Madrid.

- (1.982): El materialismo cultural. Alianza Universidad, $\mathrm{n}^{\circ}$ 324, Madrid.

HERNANDO GONZALO, A. (1.987): ¿Evolución cultural diferencial durante el Calcolítico entre las zonas áridas y húmedas el Sureste español? Trabajos de Prehistoria 44: 171-200.

- : (1.988): Evolución interna y factores ambientales en la interpretación del Calcolítico del Sureste de la Península Ibérica: una revisión crítica. Col Tesis Doctorales. no 188/88. Ed. de la Universidad Complutense. Madrid. 
—_: (1.988b): Los estudios prehistóricos: evolución y perspectivas. Métodos y tendencias actuales en la investigación geográfica y prehistórica. Estudios de Geografia e Historia 1: 49-56.

- (e.p.): Interpretaciones culturales del Calcolítico del Sureste Español. Estudio de sus bases teóricas. Cuadernos de Prehistoria de la Universidad de Granada

HODDER, I (1.979): Social and economic stress and material culture patterning. American Antiquity 44: 446454.

: (1.982a): Theoretical archaeology: a reactionary view. En I. Hodder (Ed.): Symbolic and structural Archaeology . Cambridge University Press. Cambridge, pp: 1-16.

- (1.982b): Symbols in action. Cambridge University Press. London.

- (1.984): Archaeology in 1.984. Antiquity 58: 25-32.

— : (1.987): La Arqueología en la era Post-moderna. Trabajos de Prehistoria 44: 11-26.

- - (1.988): Interpretaciones en Arqueología. Ed. Crítica, Barcelona.

- (1.989): Comments on Archaeology into the 1.990s. Norwegian Archaeology Review 22, №1:15-18.

_- : (1.991): Interpretative archaeology and its role. American Antiquity 56(1): 7-18.

HODDER, I. y ORTON, C. (1.976): Spatial analysis in Archaeology. Cambridge University Press.

HUNTER, M. (1.973): Archaeology and ethnology. In C. Renfrew (ed.): The Explanation of Culture Change. Duckworth, London. Pág. 481-92.

JOHNSON, A. y EARLE, T.K. (1.987): The evolution of human societies: from forager group to agrarian state. Standford University Press. Standford.

KLEJN, L.S. (1.971): La arqueología en Gran Bretaña: un punto de vista marxista. Cuadernos de Antropología Social y Etnología 3:25-40.

- (1.973): Marxism, the systemic approach and archaeology. In C. Renfrew (ed.): The Explanation of Culture Change: Models in Prehistory. Duckworth, London. Pág.691-710.

KOHL, P. (1.981): Materialist approaches in Prehistory. Annual Review of Anthropology. 10: 89-118.

_- (1.985): Symbolic cognitive archaeology: a new loss of innocence. Dialectical Anthropology 9: 105-117.

KUHN, T.S. (1.970): The Structure of Scientific Revolutions. Chicago University Press, Chicago.

LISBOA, I.G. (1.985): Meaning and messages: mapping style in the Iberian Calcolithic. Archaeological Review from Cambridge 4:2, pp.181-196.

MALES, A. (1.986): Past and Present of the Andean Indian society: the Otavalos. Who needs the Past? Unwin Hyman, London. pp. 95-104.

MAMAMI CONDORI, C. (1.986): History and prehistory in Bolivia: What about the indians? Who needs the Past? Unwin Hyman, London. pp. 46-59.

MARTINEZ NAVARRETE, M.I. (1.989): Una revisión crítica de la prehistoria española: la Edad del Bronce como paradigma. Siglo XXI, Madrid.

- (1.990): El arqueólogo como profesional libre en la recuperación del Patrimonio. Coferencia pronunciada en el Colegio de Doctores y Licenciados de Madrid el 12-XII-1-990. Inédito.

MELTZER (1.979): Paradigms and the nature of change in American Archaeology. American Antiquity 44:64457.

MILLER, D y TILLEY, C. (eds.)(1.984): Ideology, Power and Prehistory. Cambridge University Press. Cambridge.

MORGAN C.G. (1.973): Archaeology and explanation. Word Archaeology. 4:259-276.

ORME, B. (1.975): John Aubrey and the Realm of Learning. Duckworth, London.

PARKER PEARSON, M. (1.984): Social Change, ideology and the archaeological record. En M. Spriggs (ed.): 59-71.

PIGGOT, S. (1.950): William Stukeley: An Eighteenth-Century Antiquary. Oxford University Press.

PREUCEL, R.W. y EARLE, T.K. (1.986): Processual Archaeology and the Radical Critique. Paper presented at the World Archaeological Congress, Southamptom, England, September 5, 1.986.

RAMOS MILLAN, A. (1.981): Interpretaciones secuenciales y culturales de la Edad del Cobre en la zona meridional de la Península Ibérica. Cuadernos de Prehistoria de la Universidad de Granada 6: 203-256.

RATHJE, W.L. y SCHIFFER, M.B. (1.982): Archaeology. Harcourt Brace Jovanovich, New York. 
RENFREW, C (1.982): Explanation revisited. En C. Renfrew, M.J. Rowlands y B. Abbot Segraves (eds.): Theory and explantion in Archaeology: The Southampton Conference. Academic Press, New York, pp.5-23.

- (1.989): Comments on Archaeology into the 1.990s. Norwegian Archaeological Review 22, №1:33-41.

ROWLANDS, M. (1.984): Objetivity and subjetivity in archaeology. en M. Spriggs (ed): 108-113.

RUIZ RODRIGUEZ, A. (1.989): De las arqueologías a la Arqueología. En 1.978-1.988 Andalucia: diez años de cultura. Consejería de Cultura: 11-17.

RUIZ RODRIGUEZ, A. CHAPA BRUNET, T. y RUIZ ZAPATERO, G. (1.988): La Arqueología contextual: una revisión crítica. Trabajos de Prehistoria 45:11-17.

RUIZ RODRIGUEZ, A, HORNOS MATA, F. y MOLINOS MOLINOS, M. (e.p.) Teoría de la arqueolgía en la conservación del patrimonio. I Coloquio Hispano-Mexicano de Teoría, Método y Conservación en Arqueología. Castillo de Magalia. Las Navas del Marqués (Avila) 1.988.

RUIZ ZAPATERO, G. (1.991): Arqueología y Universidad. La "Reproducción del sistema". Revista de Arqueología. Febrero 1.991: 6-7.

SCHIFFER, M.B. (1.988): The structure of Archaeological Theory. American Antiquity 53 (3): $461-485$.

SEMENOV, S.A. (1.981): Tecnología prehistórica. Estudio de las herramientas y objetos antiguos a través de las huellas de uso. Akal Editor, Madrid.

SHANKS, M y TILLEY, C. (1.982): Ideology, symbolic power and ritual communication: A reinterpretation of Neolithic mortuary practiques. En I Hodder (Ed.): Symbolic and structural Archaeology . Cambridge University Press. Cambridge, pp: 129-154.

—: (1.987a): Re-constructing Archaeology. Cambridge University Press.

- (1.987b): Social Theory and Archaeology. Polity Press, Oxford.

- (1.989): Archaeology into the 1990s. Norwegian Archaeological Review 22, №1:1-12.

SHENNAN, S. (1.982): Ideology change and the european early Bronze Age. En I Hodder (Ed.): Symbolic and structural Archaeology. Cambridge University Press. Cambridge, pp: 155-161.

SPRIGGS, M. (Ed.) (1.984): Marxist perspectives in Archaeology Cambridge University Press. Cambridge.

STERUD, E.L. (1.973): A paradigmatic view of prehistory. In C. Renfrew (ed.): The Explanation of Culture Change: Models in Prehistory. Duckworth, London. Päg.3-17.

STUTT, A. y SHENNAN, S. (1.990): The nature of Archaeological arguments. Antiquity 64: 766-777.

TAYLOR, W.(1.948): A Study of Archaeology. Memoir 69. American Anthropological Association.

TILLEY, C. (1.981): Conceptual frameworks for the explanation of sociocultural change. En I. Hodder, G. Isaac y N. Hammond (eds.): Patterns of the Past Camridge University Press. Cambridge, pp. 363-386.

- (1.984): Ideology and the legitimation of power in the middle Neolithic of southern Sweden. en D. Miller y C. Tilley (eds.): pp. 111-146.

TRIGGER, B. (1.978): Time and Traditions. Essays in archaeological interpretations. Edinbourgh University Press. Edinbourgh

- : (1.989): A History of Archaeological Thought. Cambridge University Press. Cambridge.

- (1.990): The 1.990s: North American Archaeology with a human face? Antiquity 64: 778-787.

VICENT GARCIA, J.M. (1.985): Bases teórico-metodológicas para el estudio del comienzo de la producción de alimentos. Memoria de licenciatura. Universidad Autónoma de Madrid. Inédita

- (1.991): Arqueología y Teoría Crítica. Trabajos de Prehistoria 48. e.p..

WARTOFSKY, M.W. (1.978): Introducción a la Filosofía de la Ciencia. Alianza Universidad no 38, Madrid.

WATSON, P.J. y FOTIADIS, M. (1.990): The Razor's Edge: Symbolic-Structuralist Archaeology and the Expansion of Archaeological inference. American Anthropolist 92: 613-629.

WATSON, P.J., LeBLANC, S.A. y REDMAN, C.H.L. (1.974): El método científico en Arqueología. Alianza Universidad, Madrid ( $1^{\text {a }}$ ed.

inglesa 1.971 )

WILLEY, G.R. y SABLOFF, J.A. (1.974): A history of american archaeology. Thames and Hudson, London. 